\title{
Induced Systemic Protection Against Tomato Late Blight Elicited by Plant Growth-Promoting Rhizobacteria
}

\author{
Zhinong Yan, M. S. Reddy, Choong-Min Ryu, John A. McInroy, \\ Mark Wilson, and Joseph W. Kloepper
}

First, second, third, fourth, and six authors: Department of Entomology and Plant Pathology, Auburn University, AL 36849; and fifth author: Biology Department, The Colorado College, Colorado Springs 80903. Accepted for publication 16 August 2002.

\section{ABSTRACT}

Yan, Z., Reddy, M. S., Ryu, C.-M., McInroy, J. A., Wilson, M., and Kloepper, J. W. 2002. Induced systemic protection against tomato late blight elicited by plant growth-promoting rhizobacteria. Phytopathology 92:1329-1333.

Two strains of plant growth-promoting rhizobacteria (PGPR), Bacillus pumilus SE34 and Pseudomonas fluorescens 89B61, elicited systemic protection against late blight on tomato and reduced disease severity by a level equivalent to systemic acquired resistance induced by Phytophthora infestans or induced local resistance by chemical inducer $\beta$-amino butyric acid (BABA) in greenhouse assays. Germination of sporangia and zoospores of $P$. infestans on leaf surfaces of tomato plants treated with the two PGPR strains, pathogen, and chemical BABA was significantly reduced compared with the noninduced control. Induced protection elicited by PGPR, pathogen, and BABA were examined to determine the signal transduction pathways in three tomato lines: salicylic acid (SA)hydroxylase transgenic tomato $(n a h G)$, ethylene insensitive mutants $(\mathrm{Nr} / \mathrm{Nr})$, and jasmonic acid insensitive mutants (defl). Results suggest that induced protection elicited by both bacilli and pseudomonad PGPR strains was SA-independent but ethylene- and jasmonic acid-dependent, whereas systemic acquired resistance elicited by the pathogen and induced local resistance by BABA were SA-dependent. The lack of colonization of tomato leaves by strain 89B61 suggests that the observed induced systemic resistance (ISR) was due to systemic protection by strain 89B61 and not attributable to a direct interaction between pathogen and biological control agent. Although strain SE34 was detected on tomato leaves, ISR mainly accounted for the systemic protection with this strain.
Late blight, caused by Phytophthora infestans (Mont.) de Bary, is an economically important disease of tomato (Lycopersicon esculentum Mill.). Disease management strategies primarily depend on sanitary practices and well-timed fungicide applications (11). However, development of fungicide resistance within populations of $P$. infestans has become a problem (11), and alternative approaches that can be incorporated into integrated pest management of tomato late blight disease are needed.

Systemic acquired resistance (SAR) against late blight was previously demonstrated in tomato by inoculating $P$. infestans $(4,9,13)$ or Tobacco necrosis virus (TNV) (1) or by applying chemicals onto tomato (6) prior to challenge with the pathogen. Studies have shown that plant growth-promoting rhizobacteria (PGPR) can be applied on a wide range of plants for the purpose of disease control and growth enhancement $(15,22)$. Induced systemic resistance (ISR) has been reported as one of the mechanisms by which PGPR reduce plant disease through the manipulation of the host plant's physical and biochemical properties $(15,22)$. PGPR-elicited ISR has been demonstrated in many plant species, including Arabidopsis spp., bean, carnation, cucumber, radish, tobacco, and tomato (22). There are no reports of PGPRelicited ISR against late blight on tomato.

With SAR, inoculation of the lower leaves of tomato with $P$. infestans caused the induction of resistance on the upper leaves where germination of the fungal spores was reduced in comparison with nontreated plants (13). Kovats et al. also observed SAR against late blight disease in tomato (16). On the leaf surface of nontreated plants, $21 \%$ of the initially inoculated zoospores were

Corresponding author: J. W. Kloepper; E-mail address: jkloeppe@acesag.auburn.edu

Publication no. P-2002-1024-01R

(C) 2002 The American Phytopathological Society found as germinated cysts; whereas, on induced plants, $14 \%$ of zoospores were germinated cysts. The different levels of induced resistance correlated positively with reduction of zoospore germination on the leaf surface.

Localized infection of one part of a plant can result in the systemic expression of resistance in other parts; therefore, it has been hypothesized that a signal is generated and mobilized from the initial infection site (7). Salicylic acid (SA), jasmonic acid (JA), and ethylene apparently are involved in signaling pathways. The importance of SA in SAR signal transduction was documented using transgenic tobacco engineered to express the SAhydroxylase gene (nahG) (12). Jasmonate signaling during SAR has been studied in other plant-pathogen systems $(10,20)$. Some evidence has shown that treatment of the plants with methyl jasmonate induced the accumulation of an antifungal defensin, but not of pathogenesis-related (PR) protein PR-1. In contrast, application of SA or isonicotinic acid (INA) caused the accumulation of PR-1, but not of defensins. This finding suggested the presence of two different pathways, both inducible by pathogens. One pathway led to PR-protein expression via SA. The other pathway, via jasmonate, led to the accumulation of defensins (18). Bowling et al. (3) placed JA and SA in parallel pathways and proposed that the definition of SAR in Arabidopsis spp. should include both pathways. Ethylene is a volatile plant hormone that is involved in numerous physiological processes, including induced resistance (2). In particular, ethylene has played a role in the induction of SAR against tomato late blight (21).

The objectives of this research were to determine whether PGPR strains with known ISR activity in other crops could induce systemic protection against tomato late blight and, if so, whether ISR was involved. The potential signal transduction pathways for bacilli PGPR are reported for the first time. A portion of this work was previously reported in abstract form (24). 


\section{MATERIALS AND METHODS}

PGPR strains and inoculum preparation. Four PGPR strains (Bacillus pumilus SE34, Pseudomonas fluorescens 89B61, B. cereus $\mathrm{C} 10$, and Brevibacillus brevis 1PC11) that previously showed significant ISR activity on other crops were used in these studies $(14,15,17,23)$.

For long-term storage, bacterial strains were maintained at $-80^{\circ} \mathrm{C}$ in tryptic soy broth (TSB) (Difco Laboratories, Detroit) amended with 20\% (vol/vol) glycerol. Bacterial inoculum was prepared by harvesting cells from tryptic soy agar (TSA) plates incubated at $28^{\circ} \mathrm{C}$ for $24 \mathrm{~h}$. Inoculum was suspended in sterile distilled water (SDW) and adjusted turbidimetrically to $\approx 10^{8} \mathrm{CFU} / \mathrm{ml}$.

Fungal culture and inoculum. Phytophthora infestans race 1 was obtained from R. M. Bostock, Department of Plant Pathology, University of California, Davis. The culture was maintained on Rye B medium, prepared by mixing $150 \mathrm{ml}$ of rye seed exudate with $18 \mathrm{~g}$ of agar and $0.05 \mathrm{~g}$ of $\beta$-sitosterol dissolved in $1 \mathrm{ml}$ of ethyl ether and adjusting to 1 liter. Rye seed exudate was prepared by boiling of $120 \mathrm{~g}$ of germinated rye seed in $150 \mathrm{ml}$ of water and adding $20 \mathrm{~g}$ of sucrose. For experimental use, the culture was grown on Rye B medium at $26^{\circ} \mathrm{C}$ in the dark for 14 days. Plates then were placed at $5^{\circ} \mathrm{C}$ for $2 \mathrm{~h}$ and returned to room temperature. SDW $(10 \mathrm{ml})$ was added to each plate for zoospore release. The zoospore density was determined using a hemacytometer.

Induced systemic protection of PGPR against tomato late blight. Tomato cv. Solar Set, which is susceptible to P. infestans, was used in all experiments. Treatments included four PGPR strains and a nontreated control. Soilless growth media (Pro-mix, Premier, Peat Ltd., Rivière-du-Loup, Québec, Canada) and 10-cm-diameter plastic pots were used to produce the seedlings. At the time of seeding, PGPR suspensions were incorporated into soilless growth media at the concentration of $1.0 \times 10^{8} \mathrm{CFU} / \mathrm{g}$ and two tomato seeds were planted in each pot. Seed receiving only SDW served as the nontreated control. One week after planting, tomato seedlings were thinned to one per pot. Each treatment was replicated eight times using one pot per replication for PGPR

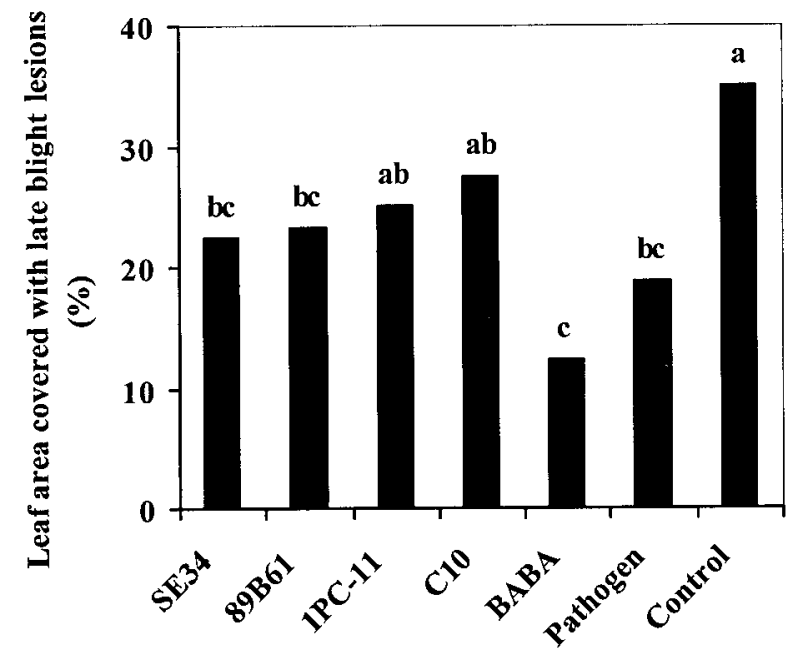

Treatments

Fig. 1. Effect of selected plant growth-promoting rhizobacteria (PGPR) strains on tomato late blight control under greenhouse conditions. PGPR strains were inoculated into soilless media when planting, and $\beta$-amino butyric acid (BABA) was sprayed onto the whole plant 7 days before challenge (DBC). For systemic acquired resistance control, zoospores of Phytophthora infestans were placed onto two bottom leaves 7 DBC. Disease was visually measured by percent leaf area covered with late blight lesions. Data are the means of three experiments. Different letters indicate significant differences among treatments according to a least significant difference test $(P=0.05)$. treatments and three pots per replication for the nontreated control. The pots were arranged in a randomized complete block (RCB) design on a greenhouse bench. Seedlings were allowed to grow for 4 weeks at $25 \pm 2^{\circ} \mathrm{C}$ under natural light. They were fertilized with Peter's light fertilizer (NPK 20-10-20) once a week and watered regularly.

At 4 weeks after seeding, nonbacterized seedlings received the following treatments. One-third of the seedlings were sprayed with DL- $\beta$-amino butyric acid (BABA) at $50 \mathrm{ppm}$. Another third were inoculated with $P$. infestans at approximately 5,000 zoospores per $\mathrm{ml}$. The remaining nontreated plants served as noninduced controls. Seven days after induction, all of the plants from various treatments were challenge inoculated. $P$. infestans at approximately 5,000 zoospores per $\mathrm{ml}$ was applied onto the whole plant until run-off. Plants were kept in the dark at $100 \%$ relative humidity $(\mathrm{RH})$ for $24 \mathrm{~h}$ before being returned to the growth chamber where they were maintained at 25 and $20^{\circ} \mathrm{C}$ day and night, respectively, with a $12-\mathrm{h}$ photoperiod and high RH. Five to six days after pathogen challenge, the percent leaf area covered with late blight lesions was visually determined on each leaf of the plant from every treatment. The experiments were repeated three times.

Effect of PGPR on germination of zoospores and sporangium on tomato leaves. We used the methods described by Clark and Page (5) to determine the effect of systemic protection induced by two PGPR strains on the germination of zoospores and sporangia of $P$. infestans on tomato leaf surfaces following whole plant challenge. Five treatments were used: (i) seed treatment with PGPR strain SE34 at the time of seeding (1 ml of bacterial suspension at $1.0 \times 10^{8} \mathrm{CFU} / \mathrm{ml}$ ), (ii) seed treatment with PGPR strain $89 \mathrm{~B} 61\left(1 \mathrm{ml}\right.$ of bacterial suspension at $\left.1.0 \times 10^{8} \mathrm{CFU} / \mathrm{ml}\right)$, (iii) application of BABA as a foliar spray at 4 weeks after seeding, (iv) inoculation of $P$. infestans onto the bottom two leaves, and $(v)$ nontreated control. Each treatment was replicated five times with one plant per replication. Plants were grown as described above. One week after induction with BABA and the pathogen, the third and fourth leaves from the bottom of each

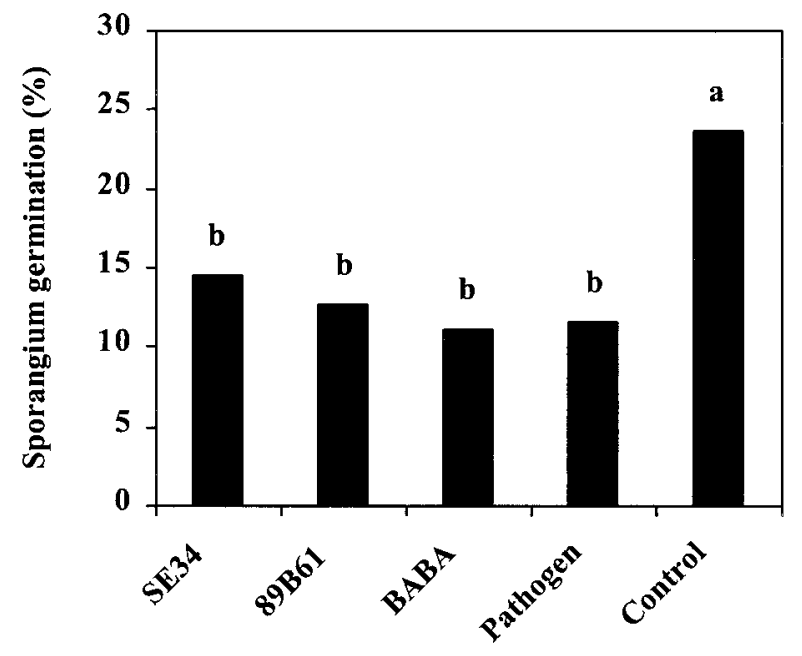

Treatments

Fig. 2. Percent germination of sporangia of Phytophthora infestans on tomato leaves induced with plant growth-promoting rhizobacteria (PGPR) strains SE34 and 89B61, $\beta$-amino butyric acid (BABA), and pathogen. PGPR were mixed into soilless media. BABA was applied on whole tomato plants 7 days before challenge (DBC). Systemic acquired resistance treatment was conducted by applying zoospores onto two bottom leaves 7 DBC. Data are means of two experiments. Different letters indicate significant differences among treatments according to a least significant difference test $(P=0.05)$. 
plant were excised and sprayed with sporangia of $P$. infestans $\left(2.0 \times 10^{4}\right.$ sporangia per $\left.\mathrm{ml}\right)$ until runoff. Leaves were placed on a wire mesh and housed in a closed humidity chamber and incubated for $8 \mathrm{~h}$ at $25^{\circ} \mathrm{C}$ in dark. The leaves then were washed in SDW to collect sporangia. The washed sporangial suspension was centrifuged at $1,700 \mathrm{rpm}$ for $10 \mathrm{~min}$. The resulting sporangial pellet was resuspended in $100 \mu \mathrm{l}$ of SDW and stained with $0.1 \%$ alanine blue. The germination of sporangia was counted under a light microscope at $\times 200$. Twenty fields of each replication were counted to calculate the percent germination of sporangia. The experiments were conducted twice.

To evaluate the effect of the above treatments on germination of zoospores, another experiment was conducted as described previously. In this experiment, leaves were sprayed with zoospores of $P$. infestans at $1.0 \times 10^{4}$ zoospores per ml until runoff, placed on a wire mesh similar to that described above, and incubated at $20^{\circ} \mathrm{C}$ for $8 \mathrm{~h}$. The leaves were washed with SDW and centrifuged at $3,000 \mathrm{rpm}$ for $10 \mathrm{~min}$. The germination of zoospores was counted under a light microscope $(\times 200)$ according to the methods described by Clark and Page (5). Twenty fields of view were counted for each replication. The experiments were conducted two times.

Determination of signal transduction pathways. To determine the main signal transduction pathways in plants induced with PGPR, bioassays were conducted on various mutant tomato plants and results compared with corresponding wild-type plants. To test involvement of SA pathways, we used $n a h G$ transgenic mutant plants of cv. Moneymaker, provided by J. Jones at the Sainsbury Laboratory, John Innes Centre, Norwich Research Park, UK. We used $N R / N R$, an ethylene insensitive homozygous mutant of cv. Pearson (ethylene sensitive), provided by S. T. Lund, Department of Plant Pathology, University of Florida. A homozygous mutant of cv. Castlemart defl/defl (provided by C. Ryan, Institute of Biological Chemistry, Washington State University), which accumulates reduced levels of JA, was used to test the role of JA during PGPR-elicited induced systemic protection.

Materials and methods for experiments of induced systemic protection were used as described above. The experiments were conducted three times, and a RCB design with eight blocks was used in all cases. Late blight disease was rated as described previously.

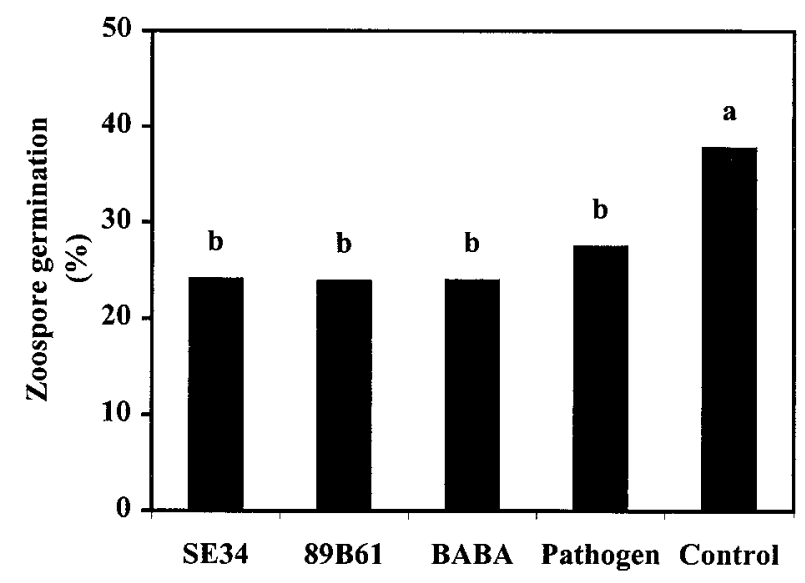

Treatments

Fig. 3. Zoospore germination of Phytophthora infestans on tomato leaves induced with plant growth-promoting rhizobacteria PGPR strains SE34 and 89B61, $\beta$-amino butyric acid (BABA), and pathogen. PGPR were mixed into soilless media when planting. BABA was applied on whole tomato plants 7 days before challenge (DBC). Systemic acquired resistance treatment was conducted by applying zoospores onto two bottom leaves 7 DBC. Data are means of two experiments. Different letters indicate significant differences among treatments according to a least significant difference test $(P=0.05)$.
Colonization of tomato plant with PGPR strains SE34 and 89B61. To determine if induced systemic protection by selected PGPR strains was due to ISR, the presence of Bacillus pumilus SE34 and Pseudomonas fluorescens 89B61 on tomato plants was monitored. Rifampicin (Rif)-resistant mutants of both strains, SE34r and 89B61r, were used in the experiments. SE34r and 89B61r were obtained by growing strains SE34 and 89B61 on TSA medium amended with Rif at $100 \mathrm{ppm}$ and selecting the

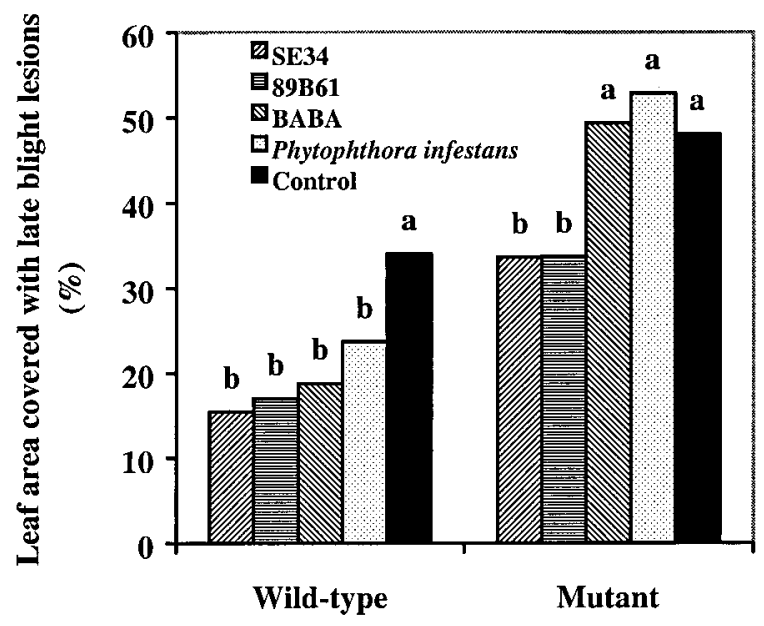

\section{nahG tomato plant}

Fig. 4. Leaf area covered with late blight lesions (\%) in $n a h G$ wild-type and mutant tomato plants after challenge with Phytophthora infestans. Plant growth-promoting rhizobacteria (PGPR) strains SE34 and 89B61 were incorporated into soilless media at planting and $\beta$-amino butyric acid (BABA) was applied onto the whole tomato plant 7 days before challenge (DBC). $P$. infestans was applied onto the two bottom leaves 7 DBC as a systemic acquired resistance control. Data are means of three experiments. Each treatment had eight replications. Different letters indicate significant differences among treatments according to a least significant difference test $(P=0.05)$.

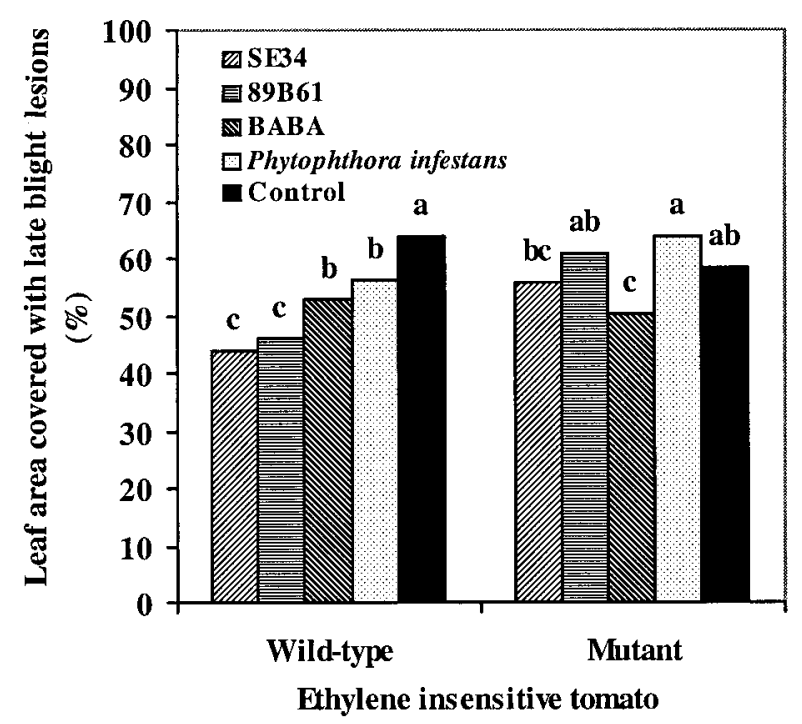

Fig. 5. Leaf area covered with late blight lesions $(\%)$ in ethylene-insensitive wild-type and mutant $(N R / N R)$ tomato plants after challenge with Phytophthora infestans. Plant growth-promoting rhizobacteria (PGPR) strains SE34 and 89B61 were incorporated into soilless media at planting and $\beta$-amino butyric acid (BABA) was applied onto whole plant 7 days before challenge (DBC). P. infestans was applied onto the two bottom leaves 7 DBC. Data are means of three experiments. Each treatment consisted of eight replications. Different letters indicate significant differences among treatments according to a least significant difference test $(P=0.05)$. 
colonies that had the same growth rate as wild-type strains. Both mutant strains were grown for $48 \mathrm{~h}$ on TSA media containing Rif at $100 \mathrm{ppm}$ and harvested with SDW. Bacterial cells were incorporated into soilless media at the rate of $10^{8} \mathrm{CFU} / \mathrm{g}$. PGPRinoculated soilless media were placed into planting trays. One tomato seed (cv. Solar Set) was seeded in each cavity of the tray. Six weeks after planting, when the tomato seedlings were the same age as pathogen-challenge inoculation in experiments of induced systemic protection, tomato seedlings were sampled. The roots, stems, and leaves were separated, weighed, and ground in a Kleco tissue pulverizer (Kleco 4200, Visalia, CA). The total bacterial population sizes on each tomato plant were estimated by spiral plating onto TSA with Rif at $100 \mathrm{ppm}$. The populations were presented as $\log _{10} \mathrm{CFU} / \mathrm{g}$ of tissue. Six replicates were used, each with one plant. The experiments were conducted twice.

Statistical analysis. All the data were analyzed by JMP program (SAS Institute, Cary, NC) using the one-way analysis of variance (ANOVA) test. Least significant difference values at $P=$ 0.05 were used to separate treatment means when ANOVA indicated a significant $F$ value.

\section{RESULTS}

Induced systemic protection of PGPR against tomato late blight. Among the four selected PGPR strains, only SE34 and 89B61 showed consistent disease protection against tomato late blight across three individual experiments (Fig. 1). Compared with the control, the average disease reduction was $42 \%$ after treatment with SE34 and 34\% with 89B61. The other two PGPR strains did not provide significant disease reduction compared with the nontreated control. The classical SAR treatment induced by pathogen and induced local resistance by chemical BABA significantly $(P=0.05)$ decreased late blight disease by 47 and $65 \%$, respectively, compared with the nontreated control. Late blight disease reduction by PGPR strains SE34 and 89B61 was not significantly different from the disease reductions obtained with SAR induced by the pathogen and local resistance induced by chemical BABA.

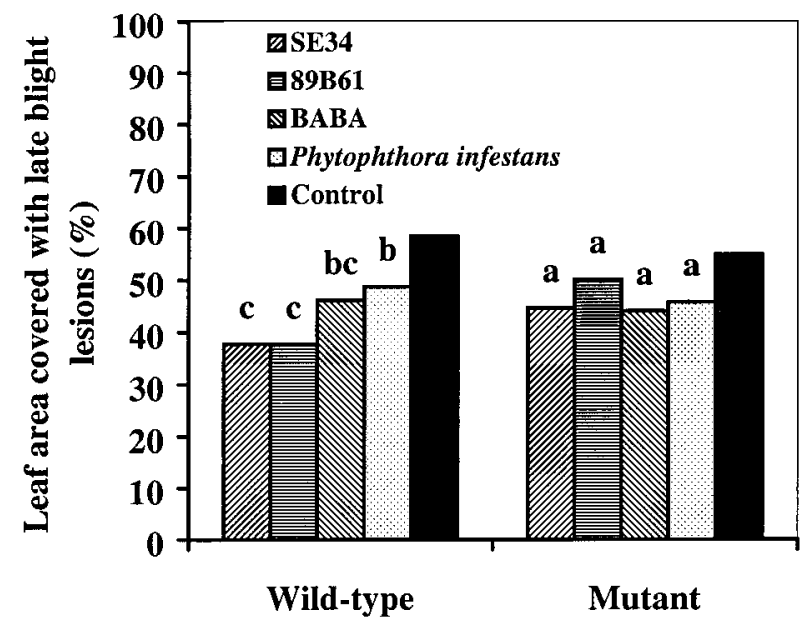

\section{Jasmonic acid tomato}

Fig. 6. Leaf area covered with late blight lesions (\%) in jasmonic acidinsensitive wild-type and mutant $(d f 1 / d f 1)$ tomato plants after challenge with Phytophthora infestans. Plant growth-promoting rhizobacteria (PGPR) strains SE34 and 89B61 were incorporated into soilless media at planting and $\beta$ amino butyric acid (BABA) was applied onto the whole tomato plant 7 days before challenge (DBC). P. infestans was applied onto the two bottom leaves at 7 DBC. Data are the means of three experiments. Each treatment consisted of eight replications. Different letters indicate significant differences among treatments according to a least significant difference test $(P=0.05)$.
Effect of PGPR on germination of zoospores and sporangium on tomato leaves. The germination of both sporangia and zoospores was significantly $(P=0.05)$ reduced on tomato leaf surfaces with all the treatments compared with the nontreated control (Figs. 2 and 3). No significant differences between PGPR treatments and classical SAR treatments were detected for either sporangium or zoospore germination.

Determination of signal transduction pathways. Treatments of two PGPR strains, BABA, and the pathogen significantly reduced late blight disease in wild-type Moneymaker tomato (Fig. 4). In $n a h G$ transgenic tomato plants, both PGPR strains significantly suppressed late blight disease compared with the control, while BABA and pathogen induction did not (Fig. 4).

In wild-type Pearson tomato, all the treatments significantly $(P=0.05)$ reduced late blight disease compared with control plants (Fig. 5). Both PGPR strains and the pathogen did not induce resistance in the ethylene mutant plants, whereas BABA significantly $(P=0.05)$ reduced the disease level (Fig. 5). Induced resistance elicited by both PGPR strains, BABA, and the pathogen significantly reduced disease severity in wild-type Castlemart tomato compared with noninduced control plants (Fig. 6). However, in defl/defl mutant plants, no treatments induced systemic resistance (Fig. 6).

Colonization of tomato plant with PGPR strains SE34 and 89B61. Colonization of tomato by Rif-resistant mutants of SE34 and 89B61 showed a different pattern. SE34r was detected on roots, stems, and leaves of tomato 6 WAP (Fig. 7). Populations on leaves were $10^{6} \mathrm{CFU} / \mathrm{g}$. In contrast, strain 89B61r was not detected on leaves (Fig. 7).

\section{DISCUSSION}

PGPR strains SE34 and 89B61 elicited systemic protection against late blight under greenhouse conditions at levels equivalent to SAR elicited by the pathogen Phytophthora infestans and induced local resistance by the chemical inducer BABA (Fig. 1). These PGPR strains previously elicited systemic protection against tomato bacterial speck (Pseudomonas syringae pv. tomato) (14), tomato bacterial spot (Xanthomonas campestris pv. vesicatoria) (23), and root knot nematode (17). The results support previous reports that systemic protection elicited by PGPR often occurs against multiple diseases $(22,25)$. Strains IPC-11 and C-10 did not significantly protect against late blight (Fig. 1), although

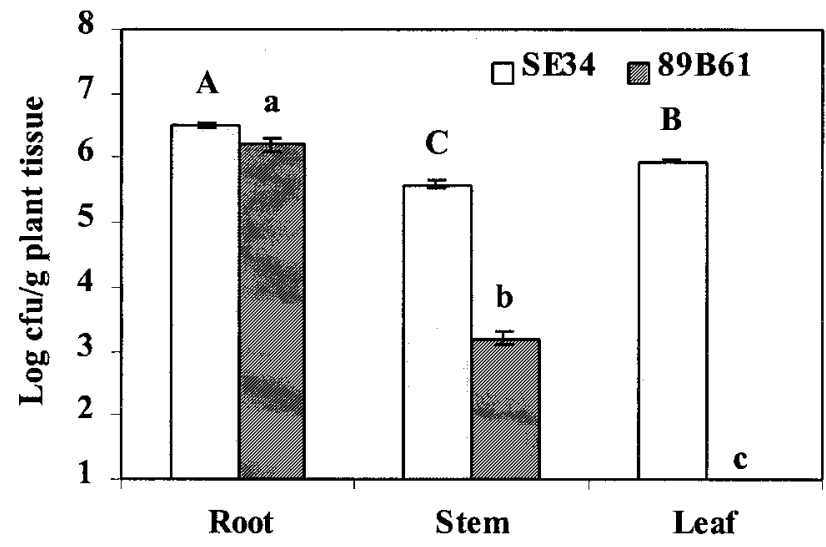

Fig. 7. Colonization of tomato seedlings by two plant growth-promoting rhizobacteria (PGPR) strains 6 weeks after planting. PGPR strains SE34 and 89B61 were incorporated into soilless media at planting. Six replicates were used, each with one plant. The data are the means of two experiments. Upper case letters $\mathrm{A}, \mathrm{B}$, and $\mathrm{C}$ indicate significant $(P=0.05)$ differences among root, stem, and leaf of tomato seedlings treated with strain SE34. Lower case letters $(\mathrm{a}, \mathrm{b}$, and $\mathrm{c})$ indicate significant $(P=0.05)$ differences for strain 89B61. 
they had protected against other tomato pathogens. Therefore, the broad-spectrum protection resulting from PGPR-ISR can be strain specific.

Germination of both sporangia and zoospores on the surface of tomato leaves was consistently reduced by PGPR strains SE34 and 89B61, BABA, and pathogen inductions $8 \mathrm{~h}$ after challenge inoculation (Figs. 2 and 3). These results are in agreement with previous reports of classical SAR induced by Phytophthora infestans in tomato (16) and potato (8). Kovats et al. (16) suggested that a major factor of the induced defense of tomato plants against $P$. infestans acted at the leaf surface and must have been operative during encystment or attachment of fungus to the plant surface. Similarly, ISR elicited by strain 89B61 likely accounted for the inhibition of germination of zoospores and sporangia of $P$. infestans on tomato leaves, because 89B61 was not detected on tomato leaves (Fig. 7). With strain SE34, however, other mechanisms besides ISR may be involved in the reduction of germination of both zoospores and sporangia of $P$. infestans due to the presence of SE34 on or in tomato leaves (Fig. 7).

Using the tomato-late blight system, PGPR-elicited systemic protection with the same two PGPR strains was examined in three tomato lines: SA-insensitive $(n a h G)$ transgenic tomatoes, ethylene-insensitive $(\mathrm{Nr} / \mathrm{Nr})$ mutants, and JA-insensitive (defldefl) mutants. These studies indicated that systemic protection elicited by both PGPR strains was SA independent but ethylene and JA dependent; however, SAR by the pathogen and chemical inducer BABA was both SA and JA dependent (Figs. 4, 5, and 6). Pieterse et al. (19) proposed that ethylene and JA were related to ISR elicited by a pseudomonad PGPR and that SA was associated with classical SAR. Our results with PGPR strains SE34 and 89B61 are in agreement with those of Pieterse et al. and demonstrate for the first time that a gram-positive PGPR strain (SE34) induces resistance via ethylene and JA-dependent pathways.

One criterion for ISR by PGPR is the physical separation of tested bacteria from target pathogens. To determine if systemic protection by SE34 and 89B61 was due to ISR, we monitored colonization of tomato seedlings by these two PGPR strains (Fig. 7). The absence of strain $89 \mathrm{~B} 61$ on tomato leaves at the time of challenge inoculation provided evidence that ISR was due to systemic protection. With strain SE34, however, leaves were colonized at a population of $10^{6} \mathrm{CFU} / \mathrm{g}$, suggesting that other mechanisms besides ISR might be involved in disease protection. Antibiosis of SE34 against $P$. infestans probably can be ruled out because no inhibition was shown when SE34 and P. infestans were grown side by side on Rye B medium plates (data not shown). Competition for nutrients on the leaf surface could partially explain the reduction of zoospore germination by strain SE34.

\section{LITERATURE CITED}

1. Anfoka, G., and Buchenauer, H. 1997. Systemic acquired resistance in tomato against Phytophthora infestans by pre-inoculation with tobacco necrosis virus. Physiol. Mol. Plant Pathol. 50:85-101.

2. Boller, T. 1991. Ethylene in pathogenesis and disease resistance. Pages 293-314 in: The Plant Hormone Ethylene. A. Mattoo and J. Suttle, eds. CRC Press, NY.

3. Bowling, S. A., Clarke, J. D., Liu Y., Klessig, D. F., and Dong, X. 1997. The cpr5 mutant of Arabidopsis expresses both NPR1-dependent and NPR1-independent resistance. Plant Cell 9:1573-1584.

4. Christ, U., and Mösinger, E. 1989. Pathogenesis-related proteins of tomato: I. Induction by Phytophthora infestans and other biotic and abiotic inducers and correlations with resistance. Physiol. Mol. Plant Pathol. 35:53-65.
5. Clark, M. C., and Page, O. T. 1968. Accumulation of hypoxanthine in potato leaves and its effect on spore germination in Phytophthora infestans. Can. J. Bot. 46:267-270.

6. Cohen, Y. 1994. Local and systemic control of Phytophthora infestans in tomato plants by DL-3-amino-n-butanoic acids. Phytopathology 84:5559.

7. Dean, R. A., and Ku•, J. 1986. Induced systemic protection in cucumber: The source of the "signal". Physiol. Mol. Plant Pathol. 28:227-236.

8. Doke, N., Ramirez, A. V., and Tomiyama, K. 1987. Systemic induction of resistance in potato plants against Phytophthora infestans by local treatment with hyphal wall components of the fungus. J. Phytopathol. 119:232-239.

9. Enkerli, J., Gist, U., and Mösinger, E. 1993. Systemic acquired resistance to Phytophthora infestans in tomato and the role of pathogenesis related proteins. Physiol. Mol. Plant Pathol. 43:161-171.

10. Farmer, E. E., Weber H., and Vollenweider, S. 1998. Fatty acid signaling in Arabidopsis. Planta 206:167-174.

11. Fry, W., and Goodwin, S. 1997. Re-emergence of potato and tomato late blight in the United States. Plant Dis. 81:1349-1357.

12. Gaffney, T., Friedrich, L., Vernooij, B., Negrotto, D., Nye, G., Uknes, S., Ward, E., Kessmann, H., and Ryals, J. 1993. Requirement of salicylic acid for the induction of systemic acquired resistance. Science 261:754756.

13. Heller, W. E., and Gessler, C. 1986. Induced systemic resistance in tomato plants against Phytophthora infestans. J. Phytopathol. 116:323328.

14. Ji, P., Wilson, M., Campbell, H. L., and Kloepper, J. W. 1997. Rhizobacterial mediated induced systemic resistance for the control of bacterial speck of fresh-market tomato. Pages 269-272 in: Plant GrowthPromoting Rhizobacteria, Present Status and Future Prospects. A. Ogoshi, K. Kobayashi, Y. Homma, F. Kodama, N. Kondo, and S. Akino, eds. Nakanishi Printing, Sapporo, Japan.

15. Kloepper, J. W., and Tuzun, S. 1996. Induced systemic to diseases and increased plant growth by growth-promoting rhizobacteria under field conditions. Phytopathology 81:1508-1516.

16. Kovats, K., Binder, A., and Hohl, H. R. 1991. Cytology of induced systemic resistance of tomato to Phytophthora infestans. Planta 183:491496.

17. Martinez-Ochoa, N., Kloepper, J. W., Rodriguez-Kábana, R., and Ji, P. 1997. Induced resistance and phenotypic characteristics of several PGPR compared to biocontrol activity against root knot nematode Meloidogyne incognita. Pages 296-300 in: Plant Growth-Promoting Rhizobacteria, Present Status and Future Prospects. A. Ogoshi, K. Kobayashi, Y. Homma, F. Kodama, N. Kondo, and S. Akino, eds. Nakanishi Printing, Sapporo, Japan.

18. Penninckx, I. A. M. A., Eggermont, K., Terras, F. R. G., Thomma, B. P. H. J., Samblanx, G. W., Buchala, A., Métraux, J. P., Manners, J. M., and Broekaert, W. F. 1997. Pathogen-induced systemic activation of a plant defensin gene in Arabidopsis follows a salicylic acid-independent pathway involving components of the ethylene and jasmonic acid responses. Plant Cell 8:2309-2315

19. Pieterse, C. M. J., van Wees, S. C. M., van Pelt, J. A., Knoester, M., Laan, R., and van Loon, L. C. 1998. A novel signaling pathway controlling induced resistance in Arabidopsis. Plant Cell 10:1571-1580.

20. Schweizer, P., Gees, R. E. M., and Mösinger, E. 1993. Effect of jasmonic acid on the interaction of barley (Hordeum vulgare L.) with the powdery mildew Erysiphe graminis f. sp. hordei. Plant Physiol. 102:503-511.

21. Spanu, P., and Boller, T. 1989. Ethylene biosynthesis in tomato plants infected with Phytophthora infestans. Plant Physiol. 134:533-537.

22. van Loon, L. C., Bakker, P. A. H. M., and Pieterse, C. M. J. 1998. Systemic resistance induced by rhizosphere bacteria. Annu. Rev. Phytopathol. 36:453-483.

23. Wilson, M., Ji, P., Campbell, H. L., and Kloepper, J. W. 1996. Development of an integrated biocontrol strategy for bacterial speck of tomato caused by Pseudomonas syringae pv. tomato. Pages 387-389 in: Advances in Biological Control of Plant Diseases. W. Tang, J. Cook, and A. Rovira, eds. Beijing Agricultural University Press, Beijing.

24. Yan, Z., Tuzun, S., and Kloepper, J. W. 1998. Evidence for PGPR-mediated induced systemic resistance against tomato late blight. (Abstr.) Phytopathology 88(suppl.):S100.

25. Zehnder, J., Wei, G., and Kloepper, J. W. 1997. Multiple disease protection by rhizobacteria that induce systemic resistance-historical procedure. Phytopathology 87:136-137. 